\title{
HORTA VERTICAL COM GARRAFAS PET: UMA ALTERNATIVA PARA EDUCAÇÃO AMBIENTAL NAS ESCOLAS
}

\section{VERTICAL KITCHEN GARDEN WITH PET BOTTLES: AN ALTERNATIVE FOR ENVIRONMENTAL EDUCATION IN SCHOOLS}

\author{
Tâmillis Lopes de ANDRADE', Edson José MAZAROTTO2², Cristiane Bezerra da SILVA ${ }^{3}$
}

1 - Bióloga. Faculdades Integradas "Espírita". Curitiba, PR, Brasil.

2 - Departamento de Patologia Básica. Programa de Pós-graduação em Microbiologia, Parasitologia e Patologia. Universidade Federal do Paraná, Curitiba, PR, Brasil.

3 - Departamento de Farmácia. Programa de Pós-graduação em Ciências Farmacêuticas. Universidade Federal do Paraná, Curitiba, PR, Brasil.

* Autor para correspondência: edmazarotto@hotmail.com

\section{RESUMO:}

A reciclagem de produtos descartáveis como garrafas PET pode ser realizada para diminuir o impacto ambiental proveniente de ações antrópicas. O fato é que para isto se faz necessário à conscientização das pessoas, sendo a escola umas das grandes ferramentas para disseminação de informações e sensibilização da comunidade. A participação dos alunos no desenvolvimento e manutenção da horta escolar é de extrema importância, pois estimula a criação de hábitos alimentares saudáveis, aumentando o consumo de hortaliças pelas crianças, bem como, ensina uma forma alternativa para destinação de resíduos descartáveis. Nesse contexto, o presente estudo teve como objetivo construir uma horta vertical utilizando garrafas PET, juntamente com alunos da 6ํㅗㄹie de uma escola em Curitiba, promovendo a criação de um espaço verde e buscando inserir os conceitos sobre sustentabilidade e educação ambiental. Durante o desenvolvimento trabalhouse os conceitos de sustentabilidade, reciclagem e educação ambiental, bem como a reutilização de materiais recicláveis, reduzindo assim a degradação do meio ambiente. Os resultados apresentaram grandes impactos positivos na formação dos alunos, tanto no comportamento ambiental como educacional. $\mathrm{O}$ estudo demonstrou que o uso de ferramentas práticas no ensino de educação ambiental são fundamentais na formação dos estudantes, auxiliando no desenvolvimento de uma sociedade mais consciente e de um desenvolvimento sustentável.

PALAVRAS-CHAVE: Educação ambiental, sustentabilidade, práticas em ciências.

\section{ABSTRACT:}

The recycling of disposable products such as PET bottles can be performed to reduce the environmental impact from human actions. The fact is that for this it is necessary to make people aware, being a school of great tools for dissemination of information and community awareness. The participation of students in developing and maintaining the school garden is extremely important because it stimulates the creation of healthy eating habits, increasing vegetables consumption by children and teaches an alternative way for allocation of disposable waste. In this context, this study aimed to build a vertical garden using PET bottles, togheter with students from 6th grade in a school in Curitiba, promoting the creation of a green space and seeking to insert the concepts of sustainability and environmental education. During the development we worked out the concepts of sustainability, recycling and environmental education, as well as the reuse of recyclable materials, thus reducing environmental degradation. The results showed a very positive influence on the formation 
of students, both in the environmental behavior as educational. The study showed that the use of practical tools in environmental education teaching are fundamental in the formation of students, assisting in the development of a more conscious society and sustainable development.

KEY-WORDS: Environmental education, sustainability, practices in science.

\section{INTRODUÇÃO}

O ciclo dos produtos na cadeia comercial não termina após serem usados pelos consumidores, esses são descartados muitas vezes em lugares indevidos. Há muito se fala em reciclagem e reaproveitamento dos materiais utilizados. Hoje, algumas empresas, estimulando a responsabilidade ambiental, já possuem projetos de recolhimento de embalagens direcionando-o para ser descartado ou reutilizado. O crescimento do poder de consumo é um problema gerado pelas novas tecnologias de fabricação, que garante a acessibilidade dos consumidores aos produtos gerando uma preocupação com o meio ambiente do novo perfil de consumidor (MUELLER, 2013).

Então, para reverter essas situações, a humanidade precisa pensar na sustentabilidade ambiental, envolvendo todos os setores da sociedade, entre eles o setor econômico, político, educacional e de saúde. Pois, é através da sustentabilidade que proporcionará qualidade de vida, atendendo às necessidades do presente sem comprometer a capacidade de gerações futuras. Para isso toda sociedade precisa educar suas ações, estabelecer limites de consumo e isso envolve não só os consumidores, mas também as empresas que devem desenvolver produtos ecologicamente corretos e com materiais que não agridam o meio ambiente (GUAITOLINI, 2013).

Assim, a Educação Ambiental se dá por uma mudança de paradigmas que exige uma contínua reflexão e apropriação dos valores que remetem a ela, as dificuldades enfrentadas assumem características ainda mais contundentes (ANDRADE, 2000).

Existem diversos fatores que podem servir como obstáculos à implementação da Educação Ambiental nas Escolas, tais como o tamanho da área, quantidade de alunos, professores e colaboradores, predisposição destes professores em passar por um processo de treinamento, vontade da diretoria de realmente implementar um projeto ambiental que vá alterar a rotina na escola, entre outros.

A cebolinha (Allium fistulosum, L.), originária da Sibéria, é um condimento muito apreciado pela população e cultivada em quase todos os lares brasileiros, e tem rápido crescimento, o que possibilita que seja utilizada como exemplo em plantios e modelos de hortas voltado para educação ambiental (HEREDIA \& VIEIRA, 2004). 
Desta forma, o presente estudo teve como objetivo utilizar garrafas PET para criação de uma horta suspensa e a partir disso inserir os conceitos de sustentabilidade e gestão de resíduos recicláveis como alternativa ao ensino de educação ambiental na escola.

\section{MATERIAL E MÉTODOS}

O estudo foi desenvolvido na Escola Estadual Padre Colbacchini, situada no bairro Butiatuvinha, Curitiba-PR, com os alunos do $6^{\circ}$ ano do contraturno à tarde, concomitante as aulas de horta, no período de 28 de agosto a 07 de novembro de 2013.

Para o desenvolvimento do projeto, um questionário com questões relacionadas ao uso de garrafas PET e montagem de uma horta foi aplicado, com a finalidade de estabelecer o nível de conhecimento dos alunos envolvidos antes e depois das aulas. Após a aplicação do questionário, 6 aulas introdutórias foram ministradas, demonstrando a importância dos 3 Rs no processo de reciclagem, a importância da reciclagem do plástico, a contaminação por garrafas PET e montagem de uma horta vertical. Com a conclusão das aulas, um novo questionário foi aplicado, com a finalidade de estabelecer o aproveitamento do conteúdo e didática aplicados. Participaram do projeto cerca de 11 alunos, entre dez e onze anos de idade.

Para a montagem da horta com garrafas PET foram utilizados os seguintes materiais; 22 Garrafas PET de 2 litros, vazias e limpas, corda de nylon para varal, tesoura, pá de jardinagem, terra preta, vermicomposto (húmus), mudas e sementes de cebolinha. Para melhor aproveitamento do tempo das aulas, as garrafas foram previamente cortadas, removendo um retângulo das laterais de aproximadamente $22 \times 8 \mathrm{~cm}$.

Foi feito também dois furos na garrafa na região próxima às extremidades superior e inferior, para servir de suporte às garrafas. O ideal é que todas tenham marcações em distâncias equivalentes, para manter a simetria quando forem penduradas. $\mathrm{Na}$ lateral oposta à abertura cortada foram feitos furos para permitir o escoamento da água em excesso.

Com as garrafas já prontas, cada aluno ficou responsável por duas garrafas para plantio, sendo que na primeira colocaram apenas a terra preta e na segunda colocaram a terra misturada com húmus produzido na escola, conforme metodologia descrita por Mazarotto \& Silva, 2016. Em cada garrafa foi plantada uma muda de cebolinha e 3 sementes da mesma, com uma distancia de aproximadamente $5 \mathrm{~cm}$ entre elas. 


\section{RESULTADOS E DISCUSSÕES}

Durante a aplicação das aulas e questionários, foi observado que houve um excelente aproveitamento dos conteúdos aplicados sobre o processo de reciclagem.

Iniciamos averiguando quanto à existência de horta na casa dos alunos participantes do projeto e se já conheciam a técnica de construção de horta em garrafas PET. Ao todo $62,5 \%$ dos alunos responderam possuir horta em casa e $87,5 \%$ já haviam ouvido falar da técnica anteriormente. Foi perguntado aos alunos sobre o que poderia ser feito para reduzir os danos causados pelo uso excessivo das garrafas PET. No pré e pós teste foi verificado que $75 \%$ dos alunos acreditavam que a substituição por garrafas retornáveis seria a melhor forma de redução, demonstrando que neste aspecto, a escola já havia abordado alguns assuntos relacionados à educação ambiental e reciclagem (Figura 1).

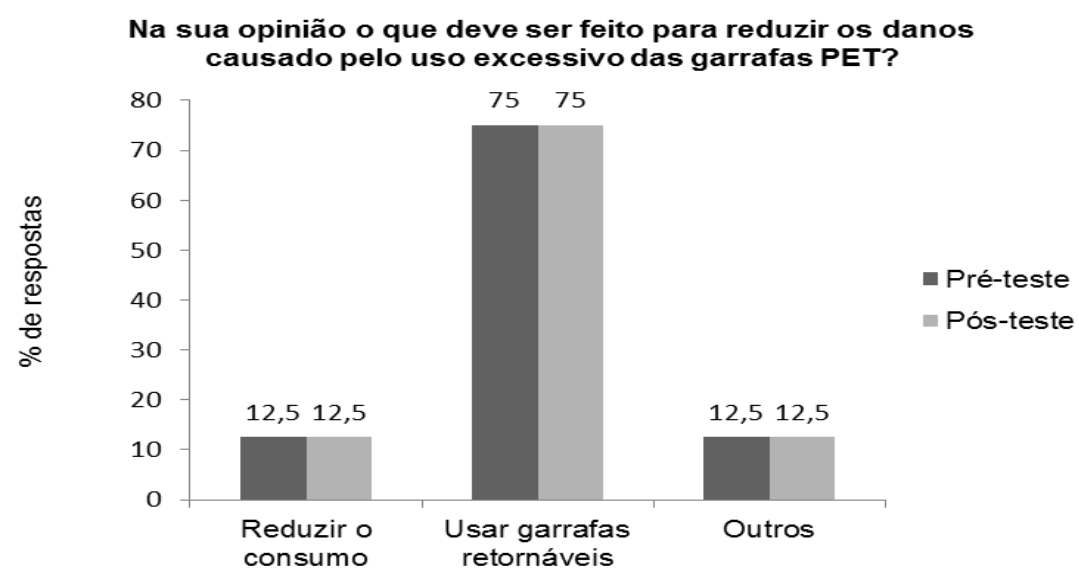

Figura 1. Porcentagem de respostas obtidas no pré e pós teste na abordagem sobre o que pode ser reduzido para reduzir os danos causados por garrafas pet.

Com base nas características dos jovens do século $\mathrm{XXI}$, o sistema educativo precisa desenvolver instrumentos para facilitar e tornar o processo de aprendizagem mais prazeroso e compatível com as habilidades perceptivas e cognitivas do aprendiz que, acostumado ao contexto comunicacional da hipermídia, lê, escuta e olha ao mesmo tempo (DILLENBOURG, 2000; SANTAELLA, 2004; MINERVINI, 2005;).

Dessa forma, fica claro que a interdisciplinaridade dentro da escola torna-se uma maneira de organizar e produzir conhecimento, buscando integrar as diferentes dimensões dos fenômenos estudados pelas disciplinas ou áreas científicas. Pretende superar uma 
visão especializada e parcializada do conhecimento em direção à compreensão da complexidade e da interdependência dos fenômenos da natureza e da vida. Por isso é que podemos também nos referir à interdisciplinaridade como postura, como nova atitude diante do ato de conhecer (COSTA, 2004).

Com relação ao questionamento a respeito da utilização dos 3 R's, foi verificado que somente $12,5 \%$ dos alunos não tinham conhecimento sobre o assunto, e que após a aplicação do projeto $100 \%$ dos alunos conseguiram associar a aplicação dos 3 R's na escola (Figura 2).

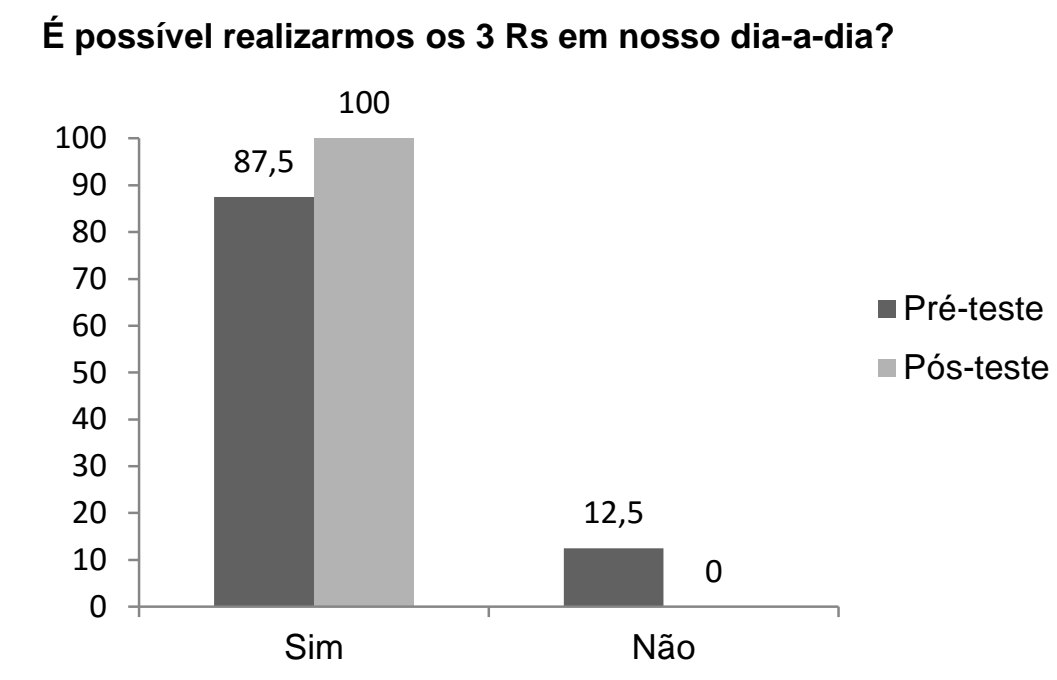

Figura 2. Porcentagem de respostas obtidas no pré e pós teste na abordagem sobre a utilização dos 3 R's no processo de reutilização de garrafas PET.

Em resumo os três R's são um conceito muito importante, tanto para se ter em mente quanto para exercitá-los. Eles não estão nesta ordem à toa. A idéia é reduzir ao máximo a produção de lixo para evitar, além da degradação do ambiente pela extração dos materiais, evitar a degradação também pelo depósito do lixo gerado. Para isto devemos atacar as duas pontas da cadeia, a produção (envolve comprar menos e melhor) e a destinação (envolve transformar o lixo em novas coisas). Reduzir, Reutilizar e Reciclar, apesar de ainda hoje serem atitudes voluntárias de algumas pessoas, já dão mostras de serem as atitudes inevitáveis a se seguir no futuro. A escassez de material para se produzir, a poluição do ar e da água, a falta de energia e outros fatores nos estão levando a um caminho que a muito já havíamos esquecido, o de que tudo um dia acaba, por maior que seja sua quantidade (Ecologia e meio ambiente, 2013).

Quando compara-se os resultados obtidos na questão que trata sobre o uso de 
garrafas PET em casa e outros ambientes (Figura 3), é verificado que houve um aumento no número de alunos que acreditam no potencial da proposta de $75 \%$ para $87,5 \%$.

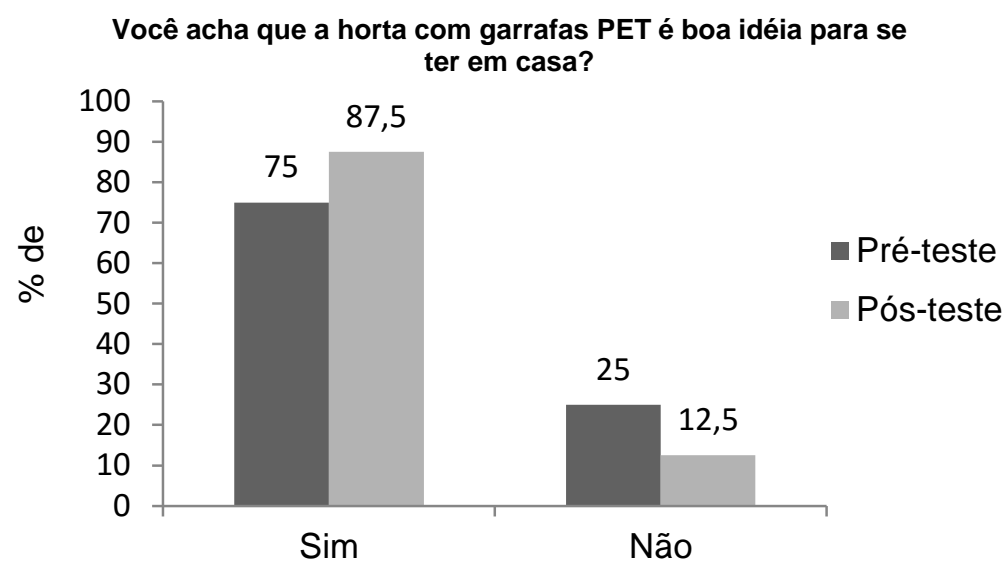

Figura 3. Porcentagem de respostas obtidas no pré e pós teste com relação ao uso de horta de garrafas PET.

Dessa forma, fica evidenciado que metodologias de ensino diversificadas tornam a explicação dos conteúdos mais claro, objetivo, compreensível e interessante para os alunos, possibilitando um maior aproveitamento em sala de aula (Jesus, 2008).

Também foi perguntado se os alunos teriam interesse em montar uma horta com garrafas PET em suas residências. Antes da aplicação do projeto, 62,5\% dos alunos demonstraram interesse em montar esse tipo de horta em suas residências, sendo verificado que com a prática, houve um aumento para $75 \%$ de aceitação pelos alunos (Figura 4).

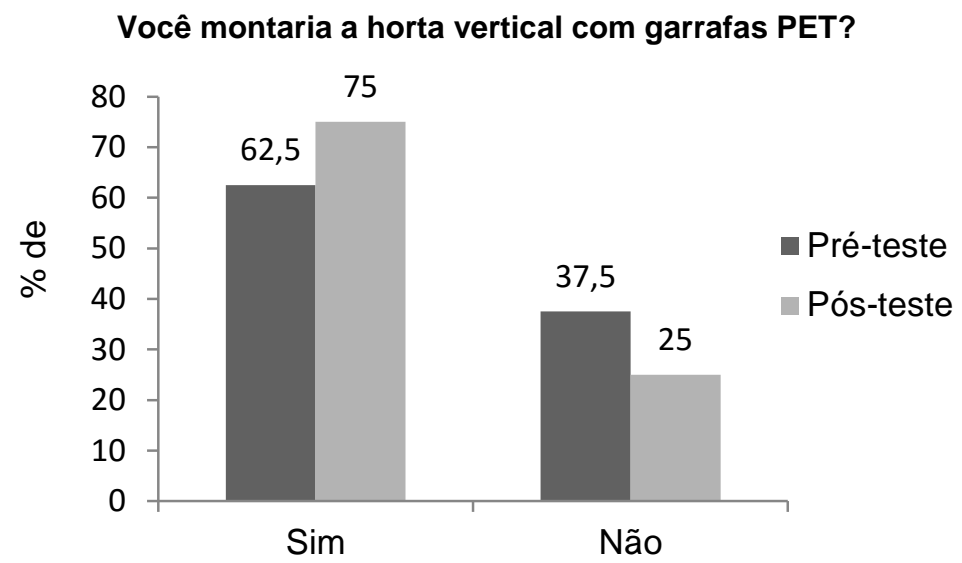

Figura 4. Porcentagem de respostas obtidas no pré e pós teste, questionando se os alunos montariam ou não uma horta vertical em sua residência. 
Segundo Jesus (2008), o professor na sala de aula é um líder, pois procura influenciar os seus alunos para que estes se interessem pelas aulas, estejam atentos, participem, apresentem comportamentos adequados e obtenham bons resultados escolares.

A figura 5 mostra os resultados obtidos para a o uso de garrafas PET em hortas como uma forma de reduzir o lixo. No pré teste $62,5 \%$ dos alunos disseram que o uso pode ser uma alternativa viável e 37,5\% acharam não ser uma alternativa. No pós teste $100 \%$ dos alunos concordaram que a técnica de horta em garrafas é sim uma forma de reduzir o lixo.

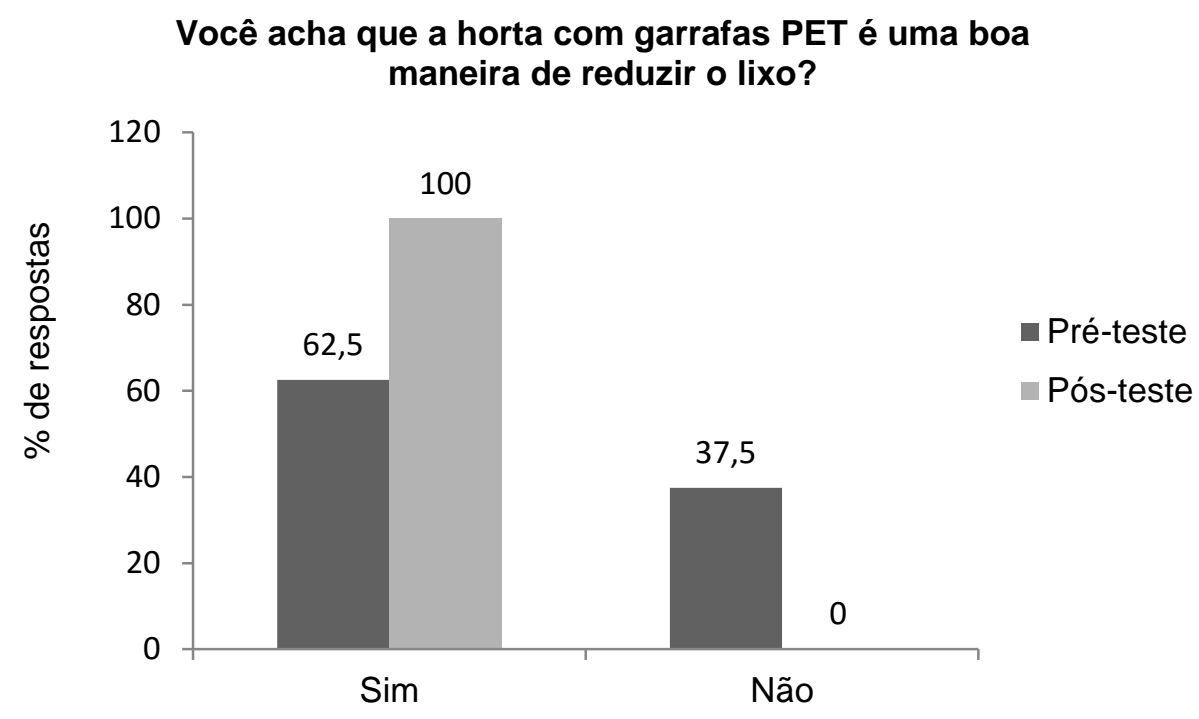

Figura 5. Porcentagem de respostas obtidas no pré e pós teste com relação ao uso de garrafas PET como uma alternativa para reduzir o lixo

Assim, é plausível inferir que a horta escolar é um elemento capaz de desenvolver temas envolvendo educação ambiental e conseqüentemente a sustentabilidade, pois além de relacionar conceitos teóricos a práticos auxiliando o processo de ensino e aprendizagem, ela se constitui como uma estratégia capaz de auxiliar no desenvolvimento dos conteúdos de forma interdisciplinar, distribuídos em assuntos trabalhados por temas transversais (SERRANO, 2003).

A horta implantada na escola em diversas vantagens para todo corpo escolar, tais como diminuir gastos com a alimentação, além de promover uma alimentação saudável, permite a colaboração dos alunos enriquecendo o conhecimento, estimula o interesse dos alunos pelos temas desenvolvidos com a horta, além de fornecer vitaminas e sais minerais 
importantes à saúde dos alunos (JARDZWSKI, 2013).

A educação ambiental precisa ser entendida como uma importante aliada do currículo escolar na busca de um conhecimento integrado que supere a fragmentação tendo em vista o conhecimento que melhor qualifique a emancipação da sociedade. Essa área de estudo e pesquisa tão necessária na contemporaneidade sustenta todas as atividades e impulsiona os aspectos físicos, biológicos, sociais e culturais dos seres humanos. Sendo assim, apresenta-se como uma peça importante no currículo escolar (VALDAMERI, 2004).

\section{CONCLUSÃo}

Concluiu-se que a aprendizagem pode ser auxiliada pela prática, melhorando hábitos atuais e futuros. Foi observado também que a utilização da horta como recurso metodológico é bastante relevante para o ensino de Ciências e Educação Ambiental, visto que além de chamar a atenção dos alunos para a observação dos fenômenos que ocorrem no processo, é uma maneira dinâmica de contextualização e de interdisciplinaridade, onde os educandos têm a oportunidade de realizar a ruptura com suas concepções alternativas, para construção de conhecimentos científicos.

\section{REFERÊNCIAS}

ANDRADE, D. F. Implementação da Educação Ambiental em escolas: uma reflexão. In: Fundação Universidade Federal do Rio Grande. Revista do Mestrado em Educação Ambiental, v. 4, p. 12-16, 2000.

COSTA, Jurandir Freire. De onde vem a Educação Ambiental? Apostila do curso de Educação Ambiental da Faculdade Católica de Uberlândia-MG, 23 p., 2004.

DILLENBOURG, P. Virtual Learning Environments. 2000. Disponível em <http://tecfa. unige.ch/tecfa/publicat/dil-papers-2/Dil.7.5.18.pdf>.

ECOLOGIA E MEIO AMBIENTE. Ser melhor. Disponivel em: <http://www.sermelhor.com /ecologia/os-tres-rs-do-consumo-consciente.html>.

GUAITOLINI, B. S. Sustentabilidade Ambiental. Disponível em: <http://www.administradores. 
com.br/informese/artigos/sustentabilidade-ambiental/23978/>.

HEREDIA, Z.N.A.; VIEIRA, M.C. Produção e renda bruta da cebolinha solteira e consorciada com espinafre. Horticultura Brasileira, v.22, n.4, p.811-814, 2004.

JARDZWSKI, K. Projeto Horta. Disponível em:<http://www.portaleducacao.com.br/ensinando/ principal/conteudo.asp?id=1357>.

JESUS, S.N. Estratégias para motivar os alunos. Educação, Porto Alegre, v. 31, p. 21-29, 2008

MAZAROTTO, E. J.; SILVA, C. B. Vermicompostagem na escola: uma alternativa sustentável para destinação de resíduos sólidos orgânicos. Visão Acadêmica, Curitiba, v.17, n.1, p. 19-30, 2016.

MINERVINI, M. A. La infografia como recurso didático. Revista Latina de Comunicación Social, n.59, p. 22- 48, 2005.

MUELLER, C. F. Meio-ambiente e Produtividade. Disponível em: <http://pessoal.facensa. com.br/girotto/files/Logistica_de_Distribuicao/logistica_reversa.pdf>.

SANTAELLA, L. Navegar no ciberespaço: o perfil cognitivo do leitor imersivo. São Paulo: Palus, 2004.

SERRANO, C. M. L. Educação ambiental e consumerismo em unidades de Ensino Fundamental de Viçosa-MG. 2003. 91 f. Tese (Doutorado em Magister Scientiae) Programa de Pós Graduação em Ciência Florestal, Universidade Federal de Viçosa, Viçosa, 2003.

VALDAMERI, A. J. Educação ambiental: um estudo de caso em escolas municipais. Dissertação (Mestrado em Engenharia de Produção Gestão da Qualidade Ambiental) Programa de Pós-graduação em Engenharia de Produção, Universidade Federal de Santa Catarina, Florianópolis, 2004. 